\title{
DIÁLOGOS AUTO(TRANS)FORMATIVOS COM PROFESSORAS DE TURMAS MULTI-IDADES NA EDUCAÇÃO INFANTIL: A ATUALIDADE DA OBRA FREIREANA E OS DESAFIOS À FORMAÇÃO INICIAL
}

\author{
JULIANA GOELZER \\ CELSO ILGO HENZ \\ Universidade Federal de Santa Maria (UFSM), Santa Maria, Rio Grande do Sul, Brasil
}

\begin{abstract}
REsUmo: Este artigo apresenta alguns dos resultados de uma pesquisa realizada com professoras de turmas multi-idades de uma Unidade de Educação Infantil, que teve o objetivo de investigar os possíveis processos auto(trans)formativos, provocados a partir da escuta sensível e do olhar aguçado às crianças nessas turmas, e os desafios colocados à formação inicial das professoras. O percurso metodológico, orientado pela Pesquisa auto(trans)formação, foi realizado a partir de Cartas Pedagógicas e de Círculos Dialógicos Investigativo-auto(trans)formativos realizados com onze professoras que atuaram/atuam nessas turmas. Os resultados evidenciam a importância da reflexão crítica na e sobre a prática, e a necessidade de (com)vivências na escuta sensível e no olhar aguçado às crianças já desde a formação inicial como princípio basilar de uma práxis humanizadora.
\end{abstract}

Palavras-chave: Auto(trans)formação com Professoras. Educação Infantil. Escuta Sensível e Olhar Aguçado. Reflexão Crítica na e sobre a Prática.

\section{PAULO FREIRE, A EDUCAÇÃO INFANTIL E A PEDAGOGIA}

Relacionar Paulo Freire à educação das crianças de 0 a 5 anos e 11 meses e à formação de suas professoras', especificamente, não é algo comum no campo da pesquisa científica, provavelmente porque, de fato, ele não dedicou sua obra às crianças e às infâncias, e em poucos momentos fez menção explícita a elas. No entanto, ainda que não tenha tratado especificamente da educação das crianças, esse educador revolucionou a maneira de se pensar e de se fazer educação de um modo mais amplo, ensinando-nos que a pedagogia, enquanto práxis humanizadora, deve cumprir o papel de acompanhar e apoiar homens e mulheres em seus processos de humanização, o que engloba, também, os processos educativos vividos pelas crianças.

Cabe destacarmos que, muito embora Freire não tivesse se debruçado sobre a temática da infância, podemos identificar, em muitas passagens de sua obra (FREIRE, 2002, 2003; FREIRE; GUIMARÃES, 2011; LACERDA, 2016, entre outras), que ele também se preocupava com a educação das crianças e com seus processos de humanização, valorizando suas singularidades e capacidades, compreendendo a importância e a necessidade de escutá-las. A título de exemplo, já em 1959, em "Atualidade e Realidade Brasileira", ao falar sobre a experiência democrática, Freire defendeu: "Interessou-nos 
sempre, e desde logo, a experiência democrática através da educação. Educação da criança e do adulto" (FREIRE, 2003, p. 14, grifos nossos).

A defesa que Freire faz por uma pedagogia crítica, dialógica, humanizadora, emancipadora, libertadora, democrática, que valorize e respeite as diferenças, é a pedagogia que defendemos para e com as crianças $^{2}$, e para a auto(trans)formação de/com suas professoras. Nessa perspectiva, compreendemos que talvez um dos pontos principais da pedagogia freireana, que tem significativa relação com as crianças, é a defesa da escuta que esse autor faz ao longo de toda a sua obra: uma escuta atenta, acolhedora, respeitosa, interessada, curiosa, disponível.

Talvez uma das passagens mais significativas de Freire em que ele se refere às crianças esteja na carta que ele escreveu, em 1990, ao educador italiano Loris Malaguzzi, idealizador da proposta para a Educação Infantil de Reggio Emilia, norte da Itália, e autor da teoria das cem linguagens da criança, quando este pediu a Freire que Ihe escrevesse uma carta dedicada às meninas e aos meninos italianos (FARIA; SILVA, [s.d.]). Freire assim escreveu:

\footnotetext{
Bom amigo Malaguzzi,

Menino eterno, pede-me, antes de eu retornar ao Brasil, que escreva algumas palavras dedicadas às meninas e aos meninos italianos. Não sei se saberia dizer algo de novo a um tal pedido. O que poderia dizer ainda aos meninos e às meninas deste final de século? Primeira coisa, aquilo que posso dizer em função de minha longa experiência nesse mundo, é que devemos fazê-lo sempre mais bonito. E baseando-me em minha experiência que torno a dizer, não deixemos morrer a voz dos meninos e das meninas que estão crescendo.

Paulo Freire, abril, 1990 (FREIRE apudFARIA; SILVA, [s.d.]).
}

Nessa carta constatamos que, já em 1990, Freire defendia que as crianças deviam ser escutadas, e tomando-se por base sua Pedagogia da Autonomia (1995), compreendemos essa escuta como aquela que atenta para as crianças em suas inteirezas (HENZ, 2003), uma escuta que vai muito além do que os ouvidos são capazes de captar.

Esse olhar tão singular de Freire com relação às crianças - que vai se revelando ao longo de uma leitura mais atenta de sua obra -, relacionado ao modo como ele defende uma práxis pedagógica humanizadora nos processos auto(trans)formativos de/com professoras e professores de modo geral, levou-nos ao interesse de relacionar esses pressupostos freireanos, pautados no que vimos qualificando como escuta sensível e olhar aguçado às crianças, com a auto(trans)formação das/com as professoras das crianças na Educação Infantil.

Em suas andarilhagens (FREIRE; HORTON, 2011), Freire olha para os diferentes povos e para seus diferentes lugares para então pensar qual pedagogia é possível naquele contexto, construindo com eles uma pedagogia que não vê a falta, mas as potencialidades daquele grupo. Isso não seria escuta sensível e olhar aguçado? E isso não estaria diretamente relacionado à práxis pedagógica com as crianças? Temos nos 
GOELZER, J.; HENZ, C. I.

preocupado em construir uma pedagogia com as crianças ou estamos construindo (repetindo?) uma pedagogia para as crianças?

Com base nessas reflexões e diante de uma realidade bastante nova - diríamos de um inédito viável (FREIRE, 2011a) - no contexto da Educação Infantil, a de turmas multi-idades, nos propusemos a investigar, com professoras dessas turmas, seus possíveis processos auto(trans)formativos vividos a partir da escuta sensível e do olhar aguçado às crianças das turmas multi-idades da Unidade de Educação Infantil Ipê Amarelo (UEIIA), uma Unidade da Universidade Federal de Santa Maria/RS, e os desafios colocados à formação inicial das professoras nos Cursos de Pedagogia a partir das reflexões geradas na e sobre a prática com essas crianças.

DENTRE AS MUITAS POSSIBILIDADES DE REINVENÇÃO DA OBRA DE FREIRE, A AUTO(TRANS)FORMAÇÃO PERMANENTE, AS CARTAS PEDAGÓGICAS E OS CÍRCULOS DIALÓGICOS INVESTIGATIVO-AUTO(TRANS)FORMATIVOS

Paulo Freire dizia que não queria ser imitado, mas sim reinventado. É isso que o Grupo Dialogus: Educação, Auto(trans)formação e Humanização com Paulo Freire, da Universidade Federal de Santa Maria/RS, vem se propondo a fazer no campo da pesquisa e da auto(trans)formação permanente com professoras e professores ao longo dos últimos dez anos, e eis o que nos propusemos na pesquisa que aqui apresentamos: reinventá-lo. Isso não significa seguir seus passos linearmente, mas a partir deles trilhar novos caminhos a partir de nossos contextos socio-histórico-político-culturais.

Nessa perspectiva, vimos construindo, no Grupo Dialogus, uma práxis de auto(trans)formação permanente com professoras/es, unindo as perspectivas teóricas de Paulo Freire (1995, 2002, 2011a, entre outras) e de Marie-Christine Josso (2010a; 2010b); propositivas a partir das quais qualificamos nossa maneira de fazer e de experienciar a pesquisa. Nossa proposta político-epistemológica, também como metodologia e como Pesquisa-auto(trans)formação, busca se ampliar e se qualificar ao entrelaçar os pressupostos freireanos com o conceito de Josso (2010b) de Pesquisaformação.

Com base na construção e na articulação teórica (sempre antes vivencial) desses autores, compreendemos fundamentalmente que a auto(trans)formação é "auto" porque é algo que acontece em mim, mas sempre comos/as outros/as e como mundo, pois não ensinamos e aprendemos sozinhos. É "trans" no sentido de transcender, de superar algo, de superar-se, de transformar-se na busca e na construção de outros e novos conhecimentos e práticas, de outros e novos sentidos na e sobre a vida, na busca e na construção de inéditos viáveis acadêmica e socialmente; assim, é "transformação" porque exige a assunção de outras posturas, de outros itinerários em nossas práxis educativas e cidadãs, em nossa vida como um todo, para assumir responsavelmente nosso lugar no Cosmos (FREIRE, 2011a).

A "formação", assim, unida ao "auto" e ao "trans", amplia o seu horizonte e comprometimento, partindo do contexto em que ela se dá e valorizando mais a nossa abertura a experiências que, vividas com os/as outros/as, partindo das nossas realidades, nos tocam, mudam o nosso olhar, nossas reflexões, nossas práticas, sempre em comunhão, com abertura ao novo. Ao olhar para o passado e para o presente projetando o futuro, apresenta-se com um grande potencial transformador, como 
possibilidade de inéditos viáveis em prol de uma educação e uma sociedade com mais bonitezas e condições de sorrir para todas as crianças e adultas/os. A formação, assim, deixa de ter um possível caráter de "treinamento", de algo "pré-pronto", vivido e executado por inúmeras pessoas, nos mais diversos contextos, para colocar-se enquanto experiência vivida em um contexto singular, onde ocorrem práticas singulares com e por um grupo singular de pessoas. É a valorização do singular no plural, partindo das experiências de vida para "re-significá-las" como "formação" (JOSSO, 2010b).

Por isso, nosso grupo não fala mais apenas em "formação de professoras/es", mas em "auto(trans)formação com professoras/es", por compreender que a formação, sem essa mudança de concepção e postura, sem essa "transformação", sem considerar todas essas nuances, deixa de ser formação. Assim, para o Grupo Dialogus, até este momento,

\begin{abstract}
Falar em auto(trans)formação com professoras/es é falar em processos que não se dão isoladamente, mas necessariamente na dialogicidade e na intersubjetividade; processos que nunca se acabam; que estão permanentemente em construção; processos que iniciam na formação inicial e se estendem continuamente durante toda a trajetória docente, sobretudo pela rigorosa reflexão sobre si e sobre sua prática. Por isso mesmo, podemos dizer que essa auto(trans)formação nunca se completa, porque somos seres inacabados; não nascemos prontos e pré-destinados a isto ou aquilo (HENZ, 2015, p. 34).
\end{abstract}

Com base nesses pressupostos freireanos e jossonianos o grupo vem, desde o ano de 2014, debruçando-se sobre uma outra alternativa metodológica que, compreendemos, abre possibilidades reais de processos auto(trans)formativos com professoras/es: os Círculos Dialógicos Investigativo-auto(trans)formativos, os quais, inspirados nos Círculos de Cultura de Freire, buscam, "[...] através do diálogoproblematizador, proporcionar uma reflexão crítica sobre o ato educativo, com um coletivo de pessoas, educadores e/ou educandos, com base nas questões levantadas pelo grupo com relação à temática" (HENZ; FREITAS, 2015, p. 75).

Essa metodologia já foi realizada em muitas pesquisas de Mestrado e Doutorado de integrantes do grupo desde 2014 e vem constituindo-se como um espaço-tempo potente de diálogos, de reflexões críticas sobre a prática, de auto(trans)formação. Nos círculos, as/os participantes - consideradas/os coautoras/es da pesquisa por ativa e autonomamente dizerem a sua palavra (FREIRE, 2011a) na elaboração dos constructos - são convidadas/os a dialogar sobre a temática de pesquisa proposta pelo/a pesquisador/a-coordenador/a; muito embora os objetivos da pesquisa devam estar bastante claros a todas/os, é papel deste/a último/a resgatá-los sempre que necessário, e nessa dinamicidade o encaminhamento do diálogo vai sendo realizado pelo grupo a partir das temáticas geradoras que vão emergindo na processualidade dialógica da imersão na realidade socioeducacional dos/as participantes.

A organização dos Círculos Dialógicos Investigativo-auto(trans)formativos, conforme têm acontecido nos encontros do Grupo Dialogus e nas pesquisas que vêm 
sendo realizadas pelas/os integrantes do grupo, acontece reconhecendo alguns movimentos, os quais não são estanques e tampouco se dão linearmente, mas vão sendo imbricados uns aos outros a partir do diálogo. Alguns movimentos já reconhecidos pelo grupo, de acordo com Henz e Freitas (2015) são: escuta sensível e olhar aguçado; descoberta do inacabamento; imersão e emersão nas temáticas, distanciamento/desvelamento da realidade, diálogos-problematizadores, registro recriativo, conscientização e auto(trans)formação.

Como revelação do nosso inacabamento, a cada encontro do grupo e/ou pesquisa realizada, os movimentos vão emergindo e compondo o diálogo, o que revela sua dinamicidade, pois ora podem aparecer, ora não, assim como podem aparecer novos movimentos não antes previstos. A propósito, na pesquisa de doutoramento da qual este artigo faz parte (GOELZER, 2020), emergiu também o desafio do reconhecimento e valorização do movimento de "pertencimento", pois na dinamicidade dos círculos, as colegas professoras foram compreendendo que constituem uma parte importante desse grupo, desse lugar, dessa história, além da sua importância na construção elaborada pelo grupo.

Os Círculos Dialógicos Investigativo-auto(trans)formativos são, assim, o principal espaço-tempo de vivências auto(trans)formativas com as/os professoras/es por meio do diálogo, da escuta sensível e do olhar aguçado. Os movimentos que surgem nesse processo nascem do diálogo e do movimento de transformação que vai acontecendo em cada um e no grupo. Nos círculos buscamos auto(trans)formações em nós mesmas/os e com as/os colegas, visando a transformações em nossas práxis educativas e esperançando mudanças na sociedade em prol de mais bonitezas e risos para todas as crianças, adolescentes, jovens e adultos/as.

Aqui cabe ainda destacarmos que, nesta pesquisa, enfatizamos e aprofundamos o movimento da escuta sensível e do olhar aguçado porque, além de estar presente na dinamicidade dos círculos, este também foi um dos conceitos principais da pesquisa, em que abordamos a escuta sensível às crianças não meramente como uma escuta de suas vozes, que se dá apenas com os ouvidos, e do mesmo modo abordamos o olhar aguçado não meramente como o olhar que se dá somente com os olhos.

$\mathrm{Na}$ mesma perspectiva em que esse movimento é compreendido durante a realização dos círculos, defendemos que a escuta sensível e o olhar aguçado, tanto na realização das pesquisas quanto nas nossas relações com os/as educandos/as - no caso desta pesquisa, com as crianças - seja de uma escuta que se dá com, a partir de um falar com, jamais de um falar de cima para baixo (FREIRE, 1995); de uma escuta do corpo, dos gestos, do silêncio, daquilo que não é dito é nem perceptível aos olhos e ouvidos, uma escuta das "entrelinhas", que acontece com todos os nossos sentidos (RINALDI, 2014).

Ainda com ênfase nessa perspectiva de escutar e olhar, também optamos, para a realização da pesquisa, pela utilização de Cartas Pedagógicas (FREIRE, 2011b, 2014, 2015; CAMINI, 2012; LACERDA, 2016) para potencializar a metodologia dos Círculos Dialógicos Investigativo-auto(trans)formativos (HENZ; FREITAS, 2015), por acreditarmos no potencial comunicativo e afetivo das cartas. Segundo Camini (2012), as Cartas Pedagógicas são uma metodologia de trabalho que cabe a nós, como desafio, dar continuidade. Freire escreveu obras lindíssimas em forma de cartas, como Cartas à Cristina (2015), Cartas a Guiné-Bissau (2011b) e Pedagogia da Indignação (2014). Essas 
cartas foram escritas com uma humanidade profunda, e as percebemos como uma maneira de se comunicar com o/a outro/a de forma realmente humana.

A pesquisa teve então uma abordagem qualitativa, abordagem em que "o termo pesquisa ganha novo significado, passando a ser concebido como uma trajetória circular em torno do que se deseja compreender, não se preocupando única e/ou aprioristicamente com princípios, leis e generalizações, mas voltando o olhar à qualidade [...]" (GARNICA, 1997, p. 111, grifos do autor), e foi definida como do tipo estudo de caso (CHIZZOTTI, 2009) por ter como foco um caso particular, a Unidade de Educação Infantil Ipê Amarelo, que foi considerada uma "referência significativa para merecer a investigação" (ibid, p. 102-103).

Tendo sido definida como Pesquisa-auto(trans)formação a partir da perspectiva freireana e jossoniana em que nos situamos, as cartas e os círculos foram, então, tomados como dispositivos de auto(trans)formação permanente a partir dos quais buscamos construir um diálogo reflexivo (FREIRE, 2011a) com as coautoras. Com o objetivo, então, de compreender os possíveis desafios que a escuta sensível e o olhar aguçado às crianças nas turmas multi-idades da Unidade de Educação Infantil Ipê Amarelo provocam para os processos auto(trans)formativos permanentes com as professoras, ao longo de cinco meses foram trocadas quatro Cartas Pedagógicas com as onze professoras coautoras da pesquisa, em que foram levantadas as temáticas geradoras para o diálogo realizado nos círculos, e realizados cinco Círculos Dialógicos Investigativo-auto(trans)formativos, sendo um deles de sistematização dos constructos com o grupo.

\section{A DO-DISCÊNCIA COM AS TURMAS MULTIIIDADES DA UEIIA E A NECESSÁRIA REFLEXÃO CRÍTICA NA E SOBRE A PRÁTICA}

O contexto desta pesquisa foi a Unidade de Educação Infantil Ipê Amarelo (UEIIA), uma Unidade da Universidade Federal de Santa Maria (UFSM) que atende, atualmente, crianças de 4 meses a 5 anos e 11 meses de toda a comunidade santamariense. A UEIIA é um espaço de Ensino, Pesquisa e Extensão que acolhe acadêmicas/os de vários cursos da UFSM e de outras instituições de Ensino Superior de Santa Maria e região - especialmente dos cursos de Pedagogia e Educação Especial -, para a realização de inserções, estágios e outras atividades formativas, constituindo-se como um espaço importante e potente na formação inicial e permanente dessas/es acadêmicas/os, e uma referência importante no trabalho pedagógico com a Educação Infantil para professoras de Santa Maria e de toda a região, com reconhecimento nacional e internacional, constituindo-se também como um espaço importante e potente no contexto da formação permanente dessas profissionais.

Nessa unidade, há mais de dez anos existem turmas multi-idades, com crianças de 18 meses/2 anos a 5 anos e 11 meses em uma mesma turma; de 2008 a 2010 existiam apenas duas turmas multi-idades (que, naquele momento, eram nomeadas de "turma integração"); de 2011 a 2015 esse número de turmas ora aumentou, ora diminuiu, bem como a idade das crianças sofreu alterações em razão das mudanças frequentes no grupo de educadoras; de 2016 até o momento a unidade organiza todas as turmas com 
multi-idades, exceto as duas de berçário, compostas por crianças de 4 meses a 18 meses/2 anos.

Por considerar essa organização curricular bastante inovadora no campo da Educação Infantil, que historicamente foi e continua sendo organizada por turmas etárias, e também como possivelmente bastante potente, desafiadora, auto(trans)formadora para o grupo de professoras que atua com as crianças nessas turmas, acreditamos que esse grupo, que foi formado pelas onze professoras que por mais tempo atuaram ao longo desses três períodos mencionados, poderia se constituir em um grupo potente para refletir acerca das auto(trans)formações possibilitadas (ou não) ao longo dessas vivências e possíveis experiências (LAROSSA, 2002). Acreditamos que, em diálogo, poderíamos trazer outras e novas inspirações também aos cursos de formação inicial de professoras nas universidades, considerando-se a inovação deste trabalho no campo da Educação Infantil.

Justamente por se tratar de algo pouco ou nunca antes experienciado pelas professoras de Educação Infantil, na processualidade dialógica vivida através das cartas e dos círculos, inicialmente a maioria das professoras revelou o seu assombro (FREIRE, 2017) inicial ao se deparar com essa organização de turmas em sua caminhada profissional e, ao mesmo tempo, os inúmeros desafios dessa atuação, o que as levou a pontuar as fragilidades de sua formação inicial; uma formação, de acordo com a compreensão do grupo, considerada técnico-instrumental. E a partir dessas "denúncias" em torno da formação inicial em Pedagogia, as professoras coautoras da pesquisa lançaram, a partir do movimento de conscientização necessário à auto(trans)formação permanente, anúncios e propositivas que podem vir a tornar tais processos mais qualificados na formação inicial no Ensino Superior.

Todas as coautoras da pesquisa mencionaram como uma das principais características da UEIIA, que a torna potente no processo auto(trans)formativo das professoras e que foi fundamental para o sucesso de suas práticas com as turmas multiidades, esse espaço de reflexão crítica na e sobre a prática em que ela se constitui, em um movimento constante de partir da prática para visitar e revisitar conceitos, e depois a ela retornar, em um movimento de realidade-conceito-realidade proposto por Freire e Faundez em "Por uma Pedagogia da Pergunta" (2017). Ana Carla ${ }^{3}$, que iniciou sua trajetória docente na Ipê Amarelo, e nesse espaço atua até hoje, destaca que

\footnotetext{
A formação inicial/continuada/permanente desempenha um papel fundamental no ser, saber e fazer do professor, e isso realmente faz a diferença, pois possibilita aprofundar e incluir novas metodologias em sua prática, contribuindo para uma Educação com mais qualidade. Só acontece uma auto(trans)formação quando se consegue fazer uma reflexão sobre a prática docente e uma relação com a teoria e a prática (terceira carta) ${ }^{4}$.
}

Para Josso (2010b), a experiência somente pode ser considerada como tal a partir do momento em que se torna um ato reflexivo. Uma auto(trans)formação requer viver uma experiência que, de fato, é o que é capaz de nos transformar. Se a experiência apenas se torna experiência mediante o processo de reflexão, então, de fato, a reflexão crítica na e sobre a prática impõe-se como necessária aos processos auto(trans)formativos das/os professoras/es. E aqui destacamos, a partir da escrita de 
Ana Carla, o quanto esse movimento tem significado para ela como professora e o quanto ela veio construindo essa reflexão em torno dos seus processos auto(trans)formativos e, ao mesmo tempo, auto(trans)formando-se por meio desses movimentos.

A reflexão crítica sobre a prática é, para Freire (2002), a dimensão fundamental da formação permanente, formação essa que se dá desde a inicial e que nunca se acaba; segundo ele, é nessa processualidade reflexiva que se dá a compreensão da teoria que funda a prática. O campo referencial da formação, desse modo, é a prática. Nas palavras do autor,

[...] na formação permanente dos professores, o momento fundamental é o da reflexão crítica sobre a prática. É pensando criticamente a prática de hoje ou de ontem que se pode melhorar a próxima prática. $\mathrm{O}$ próprio discurso teórico, necessário à reflexão crítica, tem de ser de tal modo concreto que quase se confunda com a prática (FREIRE, 1995, p. 39).

Josso (2010b, p. 100) aproxima-se muito desse conceito de Freire quando conceitua a experiência como "[...] a associação da componente factual e circunstancial à componente compreensiva", ou seja, se para esta autora a formação acontece no decorrer de uma experiência, e a experiência acontece quando buscamos compreender os fatos, também para ela a formação acontece fundamentalmente, na educação, quando refletimos sobre as nossas práticas.

Lígia, nesse sentido, destaca o potencial da Ipê Amarelo nesse movimento: "Sobre a formação de professores digo que a Ipê ensina muito, faz com que consigamos ver a teoria e prática juntas" (terceira carta). Gabriela, por sua vez, revela: "Desde que entrei na Ipê, sinto que as formações serviram muito para que eu pudesse pensar um lugar diferente como professora e oportunizar experiências distintas às crianças" (terceira carta). Assim, a Pesquisa-auto(trans)formação veio revelando que os encontros de estudo que acontecem na UEIIA, visando ao processo de reflexão crítica sobre a prática, ao passo que oportunizam nossa auto(trans)formação, oportunizam também que nós, professoras, ao repensarmos teórica e criticamente nossas práticas, possibilitemos às crianças que elas também vivenciem experiências auto(trans)formativas cada vez mais qualificadas.

Nesse viés, encontramos uma relação importante entre a docência com as turmas multi-idades da UEIIA - que com Freire vimos defendendo como do-discência (FREIRE, 1995), tendo em vista que o movimento de ensinar e aprender com as crianças é constante - e o uso sistemático da nossa curiosidade epistemológica, proposta por Freire (2002), uma vez que ficou claro nesta pesquisa que a atuação com as turmas multi-idades desafia as professoras, de forma mais constante e intensa, a refletir criticamente na e sobre a prática.

Essa relação ficou bastante clara no posicionamento da maioria das coautoras, como no da coautora Elisandra, que avaliou sua experiência nas turmas multi-idades como "a mais desafiadora, que me impulsionava diariamente a buscar novos 
conhecimentos e a trocar experiências com minhas colegas" (segunda carta). A coautora Karla também destacou que: "Estar em uma turma multi-idade provocou-me constantemente a reflexão sobre qual é o papel do professor... como deveria me organizar, como precisaria mediar as diferentes situações" (segunda carta).

Compreendemos que, em uma turma com crianças de mesma idade, justamente porque se acredita que em uma turma assim as crianças têm os mesmos interesses e necessidades, é mais fácil "manipular sutilmente" (MALAGUZZI, 1999) um projeto, um planejamento, aparentando que todas as crianças estão interessadas nas propostas e levando-as por caminhos que nós, professoras, desejamos que elas trilhem. Em uma turma com crianças de diferentes idades, tais interesses e necessidades são mais visíveis porque são bastante diferentes em cada criança; as crianças expressam os itinerários que desejam seguir e não aceitam essa "manipulação". Faz-se necessário, assim, uma escuta sensível e um olhar aguçado constante às crianças, de maneira ainda mais intensa e dedicada.

Mediante essas reflexões e articulações foi sendo compreendida, pelo grupo, a importância de repensarmos a formação que está sendo proposta em muitos cursos de formação inicial, pois por muitos anos ouvimos - e continuamos ouvindo - em muitos Cursos de Pedagogia, que o nosso papel, como professoras, é planejar cuidadosamente o que e como falar, explicar, transmitir em cada proposta, seguir projetos, planos e objetivos considerando níveis de desenvolvimento, acreditando que já sabemos tudo sobre as crianças, apesar de defendermos uma prática pautada na escuta.

Infelizmente, até hoje muitos Cursos de Licenciatura em Pedagogia parecem seguir "formando" professoras para trabalhar dessa forma tradicional com a Educação Infantil, pautados em repetições, treinamentos, em habilidades e técnicas, em ideias "pré-prontas". Em decorrência disso, muitos estudos apontam que a escuta sensível e o olhar aguçado infelizmente ainda não estão presentes em grande parte das escolas de Educação Infantil (CANCIAN; GALLINA; WESCHENFELDER, 2016), apresentando-se como urgente e necessária uma (re)aprendizagem da escuta sensível e do olhar aguçado às crianças, como centralidade de uma práxis humanizadora, que reconheça a criança em suas singularidades e como um sujeito de direitos também no campo educacional.

DAS POSSIBILIDADES AOS CURSOS DE PEDAGOGIA: POR MAIS (COM)VIVÊNCIAS NA ESCUTA SENSÍVEL E NO OLHAR AGUÇADO ÀS CRIANÇAS, INDEPENDENTE DA TURMA E DA IDADE

No decorrer da nossa Pesquisa-auto(trans)formação, as coautoras teceram considerações fundamentais acerca da importância de que essa reflexão na e sobre a prática seja vivenciada desde a formação inicial. Juliana, que passou a atuar na lpê Amarelo desde quando era acadêmica do Curso de Pedagogia, destacou, em sua terceira carta:

\footnotetext{
Uma das problematizações que surgiram em nosso último encontro foi a questão da necessidade de se repensar algumas questões da formação inicial e continuada em Pedagogia, pois bem lembrei-me de quando era acadêmica do curso de Pedagogia, pois até o terceiro semestre participei apenas de algumas observações em escolas que o curso proporcionava e possuía dificuldade de relacionar a teoria com a prática, por isso no quarto semestre do
} 


\begin{abstract}
curso busquei o estágio extracurricular na Ipê, e assim vivenciando o dia-a-dia em uma escola de Educação Infantil e estudando os textos indicados na disciplina "Contextos educativos na Infância I", realizando leituras da psicologia para compreender 0 desenvolvimento infantil, entre outros textos, fui me constituindo professora de Educação Infantil. Assim estabelecendo relação entre teoria e prática, refletindo sobre as situações cotidianas e construindo conhecimentos a partir da troca com as colegas mais experientes.
\end{abstract}

Juliana, aqui, discute o quanto foi fundamental para ela, no processo de constituir-se professora de/com a Educação Infantil, essa articulação entre a teoria estudada no Curso de Pedagogia e as vivências possibilitadas na Ipê Amarelo, revelando o movimento realidade-conceito-realidade proposto por Freire e Faundez (2017) como relevante às transformações qualificadas na prática educativa.

Ana Carla, que assim como Juliana iniciou sua atuação na Ipê Amarelo como bolsista ${ }^{5}$, ainda durante o Curso de Pedagogia, revela algo extremamente significativo:

Durante o curso estudamos o quanto é importante a escuta das crianças, porém era difícil imaginar como seria na prática, sem ter nunca vivenciado essa escuta em uma turma de crianças. No tempo de bolsista juntamente com a professora Viviane pude potencializar essa escuta sensível e aguçada, assim entendendo realmente qual o significado da escuta. Através dessas vivências na Ipê Amarelo fez com que eu despertar-se o gosto de saber algo mais, de ir além, pois foi assim que escolhi o meu tema de pesquisa no Trabalho de conclusão de curso, "Aprendizagem das crianças nos espaçostempos das turmas de multi-idade da Unidade de Educação Infantil Ipê Amarelo" [...] (primeira carta).

A escrita de Ana Carla revela dois aspectos fundamentais na construção da pesquisa aqui compartilhada: primeiro, ela traz a necessidade do que denominamos na pesquisa de "(com)vivências na escuta sensível e no olhar aguçado às crianças" no decorrer da formação inicial, ou seja, a necessidade de que as acadêmicas estejam nas escolas aprendendo a escutar e a olhar as crianças para, com elas, aprender a ser professoras, aprenderem a do-discência. Essa escuta sensível e esse olhar aguçado gerarão perguntas sobre a prática educativa, e uma professora pesquisadora estará em auto(trans)formação, tal como Ana Carla mostra que aconteceu com ela.

Esta pesquisa foi levando-nos, enquanto grupo de professoras, a refletir sobre o quanto estamos, com as práticas que têm sido realizadas na Educação Infantil, tirando das crianças essa chance de ser mais (FREIRE, 2011a), uma vez que muitas vezes parecemos não estar abertas ao imprevisto, às novidades que elas trazem, às suas singularidades e curiosidades, que precisam ser escutadas sensivelmente e olhadas aguçadamente, não sufocadas e silenciadas.

Nesse sentido, uma outra - e talvez uma das mais importantes - construções realizadas pelo grupo da pesquisa tem relação com o princípio da escuta sensível e do 
GOELZER, J.j HENZ, C. I.

olhar aguçado ser o princípio basilar, desde nossos primeiros passos na formação inicial, em nossa atuação com crianças de todas as turmas, de quaisquer idades, uma vez que nem na turma multi-idade e nem em uma turma com crianças de mesma faixa etária há como determinar tempos para as crianças, pois todas elas são diferentes, têm suas singularidades próprias.

Esse apontamento das professoras surgiu da escrita da coautora Gianna, redigida em sua segunda carta e compartilhada com as coautoras no segundo círculo e na terceira carta:

[...] todos os professores deveriam ser desafiados a passar por turmas multi-idades [...] Trabalhar com as turmas multi-idades desacomoda o modo de ver e estar com as crianças, desacomoda nosso planejamento, nossas práticas, nosso sentir, pensar e agir, pois precisamos pensar em um coletivo diverso, singular e plural, temos que pensar no grupo, mas respeitar o individual.

Bruna, mediante essa escrita de Gianna, pontuou que

[...] de fato, trabalhar numa turma multi-idades exige do professor o olhar atento, a escuta constante "pensar no grupo, mas respeitar o individual"... aí te pergunto: Não deveria ser assim em todos os tipos de turma (proposição /nível escolar)? Eu penso que sim. Então, trabalhar numa turma multi-idade é desafiador, mas quando somos professores que entendem que a individualidade de cada um deve ser respeitada e contemplada durante a prática escolar, tudo se torna desafio (quarta carta).

Elisandra, de modo semelhante, defende em sua terceira/quarta carta que "O olhar aguçado do professor deve prevalecer sempre em qualquer turma que o professor atue". E Juliana, também desafiada pela escrita de Gianna, destacou em sua quarta carta:

[...] acredito que todos os professores deveriam ser desafiados a olhar para as necessidades de cada criança independentemente da idade e pensar o planejamento e registro, pois não é porque elas tem a mesma idade que possuem os mesmos interesses ou necessidades. A única diferença é que pela turma ser multi-idade as pessoas percebem essas singularidades com mais facilidade, pois fica mais evidente (grifos da coautora).

Assim como essas coautoras mencionam, as demais também compreendem que a escuta sensível e o olhar aguçado devem ser uma prática constante na ação docente - e mais do que isso, diríamos que ela é ação docente - em qualquer turma de crianças, com quaisquer idades. E ficou bastante claro, nas falas e escritas de todas as coautoras que atuaram nessas turmas na UEIIA e que hoje atuam em outros espaços, o quanto elas conseguem perceber as singularidades de todas as crianças, ainda que estas tenham exatamente a mesma idade, como no caso de Juliana que escreveu, em sua segunda carta: "Meus alunos possuem entre 8 e 12 anos de idade, portanto também 
tenho uma turma de multi-idade, e acredito que minha experiência na Ipê me fez ser mais sensível quanto à forma de avaliar o desenvolvimento de cada um".

Com base nessas reflexões, questionamos: por que essa compreensão de que todas as crianças, de todas as idades, em qualquer turma, precisam ser escutadas de forma sensível e olhadas de modo aguçado não é tão clara assim a nós, suas professoras, desde a formação inicial no Curso de Pedagogia?

Defendemos, aqui, com base em todos esses constructos, que necessitamos de (com)vivências na escuta sensível e no olhar aguçado com as crianças de 0 a 5 anos e 11 meses ao longo da formação inicial, para que possamos aprender sobre a Educação Infantil com as crianças, para que possamos refletir criticamente na e sobre a prática e para que as crianças tenham seus processos de humanização respeitados. Defendemos que (com)vivências nos possibilitam estar com, viver com as crianças em suas escolas. Que possamos ir até a escola para escutá-las sensivelmente, olhá-las aguçadamente e com elas aprender.

\section{(IN)CONCLUSÕES: PARA NÃO DEIXARMOS MORRER A/O MENINA/O QUE FOMOS}

Os constructos elaborados junto ao grupo de professoras coautoras levaramnos a constatar que, inicialmente, a possibilidade de atuação nas turmas multi-idades assombrou essas professoras, que afirmaram não ter tido o mínimo de preparação para o enfrentamento de tal desafio. Num segundo momento, fica claro que a escuta sensível e o olhar aguçado às crianças dessas turmas provocou nessas professoras processos auto(trans)formativos com relação à importância da reflexão crítica na e sobre a prática, tão necessária nos processos auto(trans)formativos com as/os professoras/es, e com relação à necessidade de (com)vivências na escuta sensível e no olhar aguçado às crianças de todas as turmas e idades, desde a formação inicial no Curso de Pedagogia.

Tal necessidade afirma-se pela importância de que as professoras vivenciem, sintam, escutem, olhem, conheçam as crianças da, na e com a Educação Infantil ao longo da formação inicial, de modo que Ihes seja possível o movimento de construir uma pedagogia com as crianças, como uma práxis humanizadora que reconheça as crianças em suas singularidades, em suas sensibilidades, como seres humanos em processos de humanização, de emancipação, de ser mais.

Durante uma palestra proferida em 1988 na Universidade de São Paulo, aos 66 anos de idade, Paulo Freire disse: "Eu acho que uma das coisas melhores que eu tenho feito na minha vida, melhor do que os livros que eu escrevi, foi não deixar morrer o menino que eu não pude ser, e o menino que eu fui, em mim" (FREIRE, 2001, p. 101).

Que nós, professoras, também não deixemos morrer a criança que há em nós. Que não percamos a sensibilidade de nos assombrarmos, de nos encantarmos, de escutarmos para além do que escutamos com nossos ouvidos, e de olharmos para além do que vemos com os nossos olhos. Que não percamos nossa capacidade de fazer perguntas, nossa necessidade de sentir e de expressar nossa curiosidade. Que com as crianças, desde a formação inicial, estejamos sempre abertas a com elas ensinar e a aprender, a viver a do-discência, respeitando o tempo e o espaço, delas e o nosso, de vivências humanizadoras que nos constituem mais gente (FREIRE, 2011a). 
GOELZER, J.; HENZ, C. I.

Artigo recebido em: 01/04/2021

Aprovado para publicação em: 29/06/2021

\begin{abstract}
SELF(TRANS)FORMATIVE DIALOGUES WITH MULTI-AGE CLASS TEACHERS IN CHILDREN EDUCATION: THE FREIREAN PREVAILING WORK AND THE CHALLENGES TO INITIAL TRAINING
\end{abstract}

ABSTRACT: This article presents some of the research results carried out with teachers of multi-age classes in an Early Childhood Education Unit, which had the objective of investigating the possible self(trans)formative processes, caused by sensitive listening and sharp looking on children in these classes, and the challenges posed to teachers' initial training. The methodological path, guided by Research-self(trans)formation, was carried out from Pedagogical Letters and Investigativeself(trans)formative Dialog Circles carried out with eleven teachers who worked in these classes. The results show the importance of critical reflection on and about the practice and the need for (with)experiences in sensitive listening and sharp looking to children, since the initial training, is the basic principle of a humanizing praxis.

KEYWORDS: Self(trans)formation with Teachers. Child Education. Sensitive Listening and Sharp Looking. Critical Reflection on and about Practice.

DIÁLOGOS AUTO(TRANS)FORMATIVOS CON MAESTRAS DE CLASES MÚLTIPLES EN EDUCACIÓN INFANTIL: LA ACTUALIDAD DEL LEGADO FREIREANO Y LOS RETOS DE LA FORMACIÓN INICIAL

RESUMEN: Este artículo presenta algunos de los resultados de una investigación realizada con docentes de aulas con niños de varias edades en una Unidad de Educación Infantil, que tudo el objetivo de investigar los posibles procesos auto(trans)formativos, provocados por la escucha sensible y la mirada atenta de los chicos y chicas de estas clases, y los retos que plantea la formación inicial de las docentes. El camino metodológico, guiado por la Investigación-formación, se llevó a cabo a partir de las Cartas Pedagógicas y los Círculos Dialógicos Investigativo Auto(trans)formativos, realizados con once maestras que trabajaron, y/o aún trabajan, en estas clases. Los resultados muestran la importancia de la reflexión crítica en la y sobre la práctica, así como la necesidad de (con)vivencias en la escucha sensible y la mirada atenta a los niños, desde la formación inicial, como principio básico de una praxis humanizada.

PALABRAS CLAVE: Auto(trans)formación con Profesorado. Educación Infantil. Escucha Sensible y Mirada Atenta. Reflexión Crítica en la y sobre la Práctica.

\title{
NOTAS
}

1 - Neste artigo, sempre que estivermos nos referindo às professoras das crianças de 0 a 5 anos e 11 meses (dentre elas, às coautoras da pesquisa), iremos citá-las no gênero feminino em consideração ao grande número de profissionais mulheres atuantes na área. Nossa mais profunda admiração e respeito aos homens que atuam com a Educação Infantil, mas aqui, em 
reconhecimento a essas profissionais e também como uma forma de luta contra a dominação de gênero, iremos nos referir utilizando o gênero feminino.

2 - Utilizaremos a preposição "com" sempre que mencionarmos a docência com a Educação Infantil, com as crianças, por compreendermos que essa docência não se dá apenas "na" Educação Infantil, mas sim "com" a Educação Infantil, partindo da perspectiva da do-discência proposta por Freire (1995).

3 - As coautoras aparecem identificadas conforme a escolha delas: algumas optaram por manter sua identificação na pesquisa, ao passo que outras escolheram codinomes.

4 - As falas e escritas das coautoras, ao longo do processo de interpretação dos constructos, aparecem em suas formas originais (linguagem coloquial), ou conforme revisado/corrigido por elas, de modo a nos mantermos fiéis ao dito/escrito.

5 - "Bolsistas" são as/os acadêmicas/os do Curso de Pedagogia ou Educação Especial da UFSM que atuam nas turmas da UEIIA, apoiando o trabalho realizado pela professora referência. Assim como o termo "professora", o termo "bolsista" ou "acadêmica" do Curso de Educação Especial ou Pedagogia também será escrito no gênero feminino em consideração à grande maioria das mulheres que está em processo de formação inicial na área.

\section{REFERÊNCIAS BIBLIOGRÁFICAS}

CAMINI, I. Cartas Pedagógicas: aprendizados que se entrecruzam e se comunicam. São Paulo: Outras expressões, 2012.

CANCIAN, V. A.; GALLINA, S. de F. da S.; WESCHENFELDER, N. Pedagogias das Infâncias, Crianças e Docências na Educação Infantil. Santa Maria: UFSM, Centro de Educação, Unidade de Educação Infantil Ipê Amarelo; Brasília: Ministério da Educação, Secretaria de Educação Básica, 2016.

CHIZZOTTI, A. Pesquisa em ciências humanas e sociais. São Paulo: Cortez, 2009.

EDWARDS, C.; GANDINI, L.; FORMAN, G. As cem linguagens da criança: a abordagem de Reggio Emilia na educação da primeira infância. Tradução Dayse Batista. Porto Alegre: Artmed, 1999.

FARIA, A. L. G. de; SILVA, A. A. Por uma nova cultura da infância. Revista Educação. Brasil, [s.d].

FREIRE, P. Pedagogia da Autonomia: saberes necessários à prática educativa. 31. ed. São Paulo: Paz e Terra, 1995. (Coleção Leitura).

FREIRE, P. Pedagogia dos sonhos possíveis. São Paulo: UNESP, 2001.

FREIRE, P. Professora Sim, Tia Não. Cartas a quem ousa ensinar. 11. ed. São Paulo: Olho d'Água, 2002. 
GOELZER, J.; HENZ, C. I.

FREIRE, P. Educação e atualidade brasileira. $3^{\text {a }}$ ed. São Paulo: Cortez; Instituto Paulo Freire, 2003.

FREIRE, P. Pedagogia do Oprimido. 49. ed. Rio de Janeiro: Paz e Terra, 2011 a.

FREIRE, P. Cartas à Guiné-Bissau. Registros de uma experiência em processo. São Paulo: Paz e Terra, 2011b.

FREIRE, P. Pedagogia da Indignação. Cartas pedagógicas e outros escritos. São Paulo: Paz e Terra, 2014

FREIRE, P. Cartas a Cristina. Reflexões sobre minha vida e minha práxis. São Paulo: Paz e Terra, 2015.

FREIRE, P.; FAUNDEZ, A. Por uma pedagogia da pergunta. 8.ed. Rio de Janeiro / São Paulo: paz e Terra, 2017.

FREIRE, P.; GUIMARÃES, S. Partir da infância: diálogos sobre educação. São Paulo: Paz e Terra, 2011.

FREIRE, P.; HORTON, M. O caminho se faz caminhando: conversas sobre educação e mudança social. 2. ed. Trad. de Vera Lúcia Mello Josceline. Notas de Ana Maria Araújo Freire. Petrópolis, RJ: Vozes, 2011.

GARNICA, Antonio Vicente Marafioti. Algumas notas sobre Pesquisa Qualitativa e Fenomenologia. Interface - Comunicação, Saúde, Educação, Brasil, v. 1, n. 1, 1997. Disponível em: https://www.scielo.br/j/icse/a/CMZhfgQZbFHBdTjg9fFWpkd/?lang=pt. Acesso em: 06 jul. 2020.

GOELZER, Juliana. Auto(trans)formação permanente com professoras: a escuta sensível e o olhar aguçado na do-discência com as turmas multi-idades da Unidade de Educação Infantil Ipê Amarelo/UFSM. Tese de Doutorado. Tese (Doutorado em Educação) Universidade Federal de Santa Maria, Santa Maria, 2020.

HENZ, C. I. Razão-emoção crítico-reflexiva: um desafio permanente na capacitação de professores. 2003. Tese (Doutorado em Educação) - Universidade Federal do Rio Grande do Sul, Porto Alegre, 2003.

HENZ, C. I. Círculos Dialógicos Investigativos-formativos e auto(trans)formação permanente de professores. In: HENZ, C. I.; TONIOLO, J. M. dos S. de A. DIALOGUS: círculos dialógicos, humanização e auto(trans)formação de professores. São Leopoldo: Oikos, p. 73-84. 2015.

HENZ, C. I.; FREITAS, L. M. Círculos Dialógicos Investigativos- formativos: uma proposta epistemológica-política de pesquisa. In: HENZ, C. I.; TONIOLO, J. M. dos S. de A. 
DIALOGUS: círculos dialógicos, humanização e auto(trans)formação de professores. São Leopoldo: Oikos, p. 73-84. 2015.

JOSSO, M. Caminhar para si. Porto Alegre: EDIPUCRS, 2010a.

JOSSO, M. Experiências de vida e formação. São Paulo: Cortez, $2010 \mathrm{~b}$.

LACERDA, N. A casa e o mundo lá fora. Cartas de Paulo Freire para Nathercinha. Rio de Janeiro: Zit, 2016.

LARROSA, J. B. Notas sobre a experiência e o saber da experiência. Revista Brasileira de Educação, Brasil, n. 19, jan./fev./mar./abr., 2002. Disponível em: $<$ https://www.scielo.br/scielo.php?pid=S1413-

24782002000100003\&script=sci_abstract\&tlng=pt $>$. Acesso em: 16 jun. 2020.

RINALDI, C. Diálogos com Reggio Emilia: escutar, investigar e aprender. Tradução: Vania Cury. São Paulo: Paz e Terra, 2014.

JulianA Goelzer: Doutora em Educação (2020), Mestra em Educação (2014), Especialista em Gestão Educacional (2012) e Pedagoga (2010) pela Universidade Federal de Santa Maria (UFSM/RS). Professora do Ensino Básico, Técnico e Tecnolósico da Universidade Federal de Santa Maria (UFSM/RS) desde 2015, lotada na Unidade de Educação Infantil lpê Amarelo (UEIIA), onde além de professora, exerceu o cargo de Diretora do Departamento de Ensino, Pesquisa e Extensão de 2015 a 2018 e, desde 2018, exerce o cargo de Vice-diretora.

Orcid: https://orcid.org/0000-0003-2066-1589

E-mail: julianagoelzer@yahoo.com.br

CelSO ILGO HenZ: Possui graduação em Filosofia pela Faculdade de Filosofia Ciências e Letras Dom Bosco (1990), Mestrado em Educação pela Universidade Federal de Santa Maria (1995), Doutorado em Educação pela Universidade Federal do Rio Grande do Sul (2003) e Pós-Doutorado pela Universidad de Sevilla Sevilla/Espanha. Atualmente é professor titular da Universidade Federal de Santa Maria e pesquisador do PPGE, na Linha de Pesquisa: Formação, Saberes e Desenvolvimento Profissional e do PPPG, na Linha de Pesquisa: Gestão Pedagógica e Contextos Educativos.

Orcid: https://orcid.org/0000-0002-0571-5684

E-mail: celsoufsm@smail.com

Este periódico utiliza a licença Creative Commons Attribution 3.0, para periódicos de acesso aberto (Open Archives Initiative - OAI). 